\title{
Antinociceptive effects of Euphorbia helioscopia extract on Balb/c mice
}

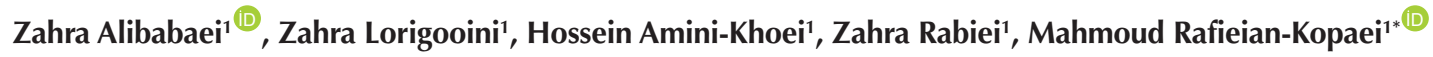 \\ ${ }^{1}$ Medical Plants Research Center, Basic Health Sciences Institute, Shahrekord University of Medical Sciences, Shahrekord, Iran.
}

*Corresponding Author: Mahmoud Rafieian-Kopaei, Medical Plants Research Center, Basic Health Sciences Institute, Shahrekord University of Medical Sciences, Shahrekord, Iran, Tel: 0098381 3346692, Fax: 00983813330709 E-mail: rafieian@yahoo.com

\begin{abstract}
Background and aims: Euphorbia helioscopia has multiple pharmacological activities, such as antibacterial, antiviral, antifungal,anticancer and/or antitumor, allelopathic, anti-allergic and anti-asthmatic, antioxidant, antinociceptive effect. The aim of the study was to evaluate the antinociceptive activities of Euphorbia helioscopia extract in Balb/c mice, as well as the total flavonoids, phenolic contents, and antioxidant activities of the extract.

Methods: In this study, $90 \mathrm{Balb} / \mathrm{c}$ mice were randomly designated into 9 groups. Group 1 received normal saline, groups 2 to 7 received different doses of the E. helioscopia hydroethanolic extract (i.e., $0.05,0.1,0.2,0.4,2$, \& $8 \mathrm{mg} / \mathrm{kg}$, i.p.).In addition, groups 8 and 9 received naloxone $(1 \mathrm{mg} / \mathrm{kg}$ ) and extract $(8 \mathrm{mg} / \mathrm{kg}$ ) plus naloxone $(1 \mathrm{mg} / \mathrm{kg}$ ), respectively (Naloxone was injected 15 minutes after extract administration). Then, pain response was evaluated for 30 minutes after the injection of $20 \mu \mathrm{L}$ formalin (1.5\%) in the plantar surface of the mice foot. Further, the beta-carotene-linoleate method was used for measuring antioxidant capacity. Finally, total phenolic and flavonoid content were measured based on Folin-Ciocalteu colorimetric and aluminum chloride colorimetric methods, respectively.

Results: Total phenol and flavonoid content were $49.43 \pm 1.8 \mathrm{mg} \mathrm{GAE} / \mathrm{g}$ dried extract and $30.19 \pm 1.96 \mathrm{mg}$ rutin/g dried extract, respectively. Our results showed that during the first 5 minutes (the acute pain step), a significant difference $(P<0.05)$ was observed between the control group and the group which received the $E$. helioscopia hydroethanolic extract ( $8 \mathrm{mg} / \mathrm{kg}$ ). In the next 25 minutes (the chronic pain step), a significant difference $(P<0.05)$ was found between the control group and the group which received $0.1 \mathrm{and} 8 \mathrm{mg} / \mathrm{kg}$ doses of the extract. Based on the results, naloxone was unable to reverse the antinociceptive effects of the extract and the maximum antioxidant activity of the extract was $1.641 \mathrm{mg} / \mathrm{g}$ of rutin equivalent.

Conclusion: In general, this study supports the use of the E. helioscopia extract in folk medicine as the analgesic agent and calls for further investigations regarding elucidating its mechanism of action. Eventually, our findings revealed that the extract of $E$. helioscopia possessed either antinociceptive or anti-oxidative activities.

Keywords: Euphorbia helioscopia, Pain, Mice, Formalin test, Antioxidant activity
\end{abstract}

Received: 12 February 2019, Accepted: 4 August 2019, ePublished: 28 February 2020

\section{Introduction}

Pain is an undesirable feeling raised from injury to tissues due to physical, chemical, thermal and electrical stimulants. In addition, it indicates the presence or possibility of danger to the organs (1). The American Academy of Pain Management reported that more than one hundred million dollars are annually paid for controlling the pain (1). Today, non-steroid anti-inflammation drugs (NSAIDs) and opioids are commonly used for pain relieving, which have relatively high side effects (2). Evidence demonstrates that NSAIDs cause harmful effects on the digestion system and kidneys and several common side effects of opioids are nausea, constipation, stupefaction and respiratory weakness, along with addiction (3). It is further indicated that medicinal plants prevent the toxic effects of synthetic drugs. Natural compounds are preferred to synthetic drugs because they do not accumulate in the body and have less side effects. Recently, pain relief experiments have focused on medical plants such as the Euphorbia genus $(4,5)$.

The herbal family of Euphorbiaceae includes 300 genus and more than 800 species that grow in most areas of the earth except for high mountain summits. Approximately 70 species of Euphorbia have been reported in Iran and 17 of them are domestic of Iran (6). Previous studies have shown that kaempferol, quercetin, and luteolin are among the most abundant flavonoids in some genera of Iranian Euphorbia (7). The presence of cycloartenol with other kinds of triterpenoids has been proved in Euphorbia species including the Iranian genus (7).

Euphorbia contains flavonoids and steroids which may be responsible for some macrocyclic diterpenoids with antibacterial, anti-cancer, prostaglandin E2 inhibition, antiHIV, and anti-pain effects of Euphorbia decipiens species $(7,8)$. Euphorbia helioscopia (E. helioscopia) is widely used

(C) 2020 The Author(s); Published by Shahrekord University of Medical Sciences. This is an open-access article distributed under the terms of the Creative Commons Attribution License (http://creativecommons.org/licenses/by/4.0), which permits unrestricted use, distribution, and reproduction in any medium, provided the original work is properly cited. 
as a decoction or infusion for treating various ailments such as intestinal parasites, diarrhoea, peptic ulcers, heartburn, vomiting, amoebic dysentery, asthma, bronchitis, hay fever, laryngeal spasms, emphysema, coughs, colds, kidney stones, menstrual problems, sterility, and venereal diseases (9). Moreover, this plant is used to treat the affections of the skin and mucous membranes, including warts, scabies, tinea, thrush, aphthae, fungal afflictions, measles, and Guinea-worm. It is considered as an antiseptic for treating the wounds, sores, and conjunctivitis as well. Not only $E$. helioscopia has the mentioned characteristics but also is reputed as an analgesic for treating severe headache, toothache, rheumatism, colic in addition to the antidote and pain relief of scorpion stings and snakebites (10).

Despite those traditional claims of E. helioscopia, the scientific evidence has not been yet reported regarding its pharmacological and phytochemical properties. Therefore, the present study aimed to investigate the antinociceptive activities of the E. helioscopia extract in the animal model using the formalin test.

\section{Materials and Methods \\ Method of Extraction}

Euphorbia helioscopia plant was identified by an expert botanist and gathered from the Gandoman region in Charmahal and Bakhtiari province. A voucher specimen was deposited in the Herbarium of Medical Plants Research Center of Shahrekord University of Medical Sciences (No. 305). The aerial parts of the plant were powdered after drying in shadow and at room temperature. To extract it by the maceration method, $1000 \mathrm{~g}$ of the powdered plant was poured in a beaker and $2000 \mathrm{~mL}$ of ethanol $70 \%$ was added to cover the powder. After 3 days, the extract was filtrated by a filter paper. The process was repeated again and the gathered extract was concentrated by a vacuum rotary evaporator. Then, the extract was reconstructed in specific volumes of normal saline to obtain different concentrations of the extract (7).

\section{Animals and Study Design}

Overall, 90 male Balb/c mice $(25 \pm 3 \mathrm{~g})$ were used in this study. Mice were kept in the animal house of Shahrekord University of Medical Sciences at a temperature of 21 to $25^{\circ} \mathrm{C}$ and had free access to food and water.

To measure the antinociceptive effect of E. helioscopia, 20 $\mu \mathrm{L}$ of formalin $1.5 \%$ was injected subcutaneously (SC) to the plantar surface of the foot 15 minutes after the i.p. injection of different doses of the extract and the mouse response to pain stimuli was immediately recorded for 30 minutes. The response to pain was considered as the time consumed for licking, biting, and lifting up the injected foot.

The mice were randomly divided into 9 groups $(n=10)$. Group 1 received normal saline and groups 2 to 7 received $0.05,0.1,0.2,0.4,2$, and $8 \mathrm{mg} / \mathrm{kg}$ of the extract, respectively. Additionally, group 8 received $1 \mathrm{mg} / \mathrm{kg}$ naloxone and group 9 was co-treated with $8 \mathrm{mg} / \mathrm{kg}$ of the extract plus naloxone (SC). Fifteen minutes after the i.p. injection of $8 \mathrm{mg} / \mathrm{kg}$ of the extract, $1.5 \%$ formalin solution (SC) was injected and the duration of mice reactions to pain was immediately measured for 30 minutes. The pain due to the injection of formalin was called acute and chronic in the first 5 and the second 25 minutes, respectively (11), Figure 1 displays the design of the present study.

\section{Determining the Amount of Phenolic Content}

The total phenolic content (TPC) was measured using the Folin-Ciocalteu colorimetric method in the gallic acid equivalent (GAE) in the grams of the dried extract. Initially, different concentrations of gallic acid and extracts were prepared in the $60 \%$ methanol solution. Then, $0.1 \mathrm{~mL}$ of each concentration was transferred to the test tube. Next, $0.5 \mathrm{~mL}$ of Folin-Ciocalteu solution $(10 \%)$ was added to each test tube, followed by adding $0.4 \mathrm{~mL}$ of $7.5 \%$ sodium carbonate solution after 3-8 minutes. After 30 minutes, the optical absorbance was read by a spectrophotometer at $765 \mathrm{~nm}$. Finally, the TPC of the extract was calculated and expressed in mg GAE/g dried extract (12).

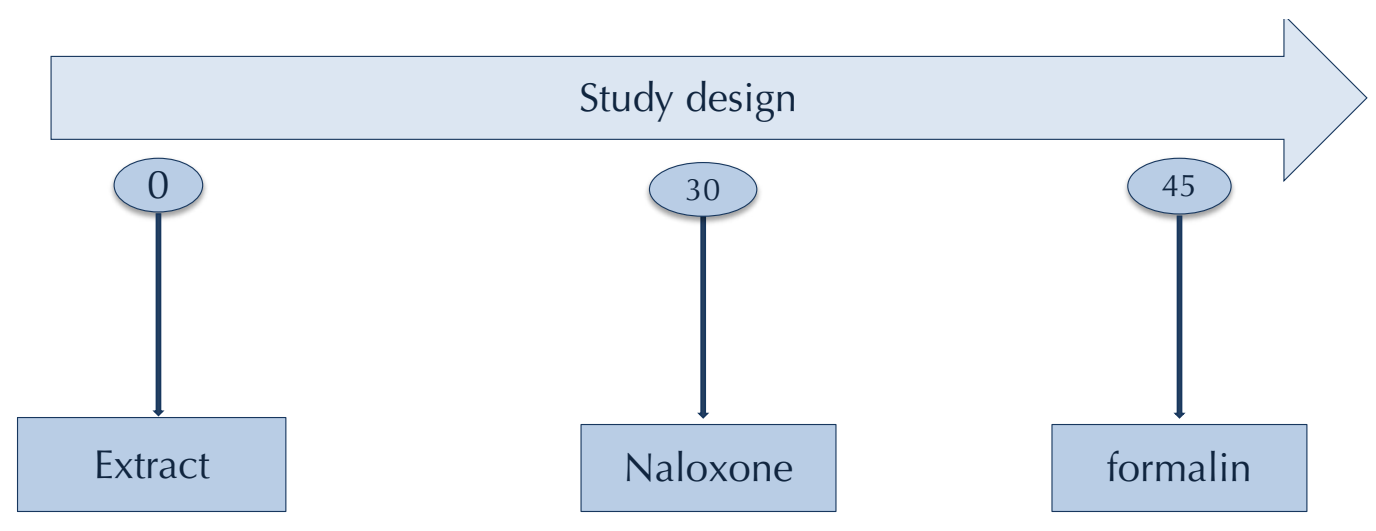

Figure 1. Study Design. 


\section{Determining the Amount of Flavonoid Content}

The aluminum chloride and rutin colorimetric method was used for measuring the total amount of flavonoids. First, the standard solutions of Rutin with concentration levels of 25, 50,100,250, and $500 \mathrm{ppm}$ were prepared and then $1 \mathrm{~mL}$ of these solutions was transferred to the test tubes and mixed with $1 \mathrm{~mL}$ of chloride aluminum $2 \%$. Next, $6 \mathrm{~mL}$ potassium acetate $5 \%$ was added and the optical density level was read after 40 minutes at $415 \mathrm{~nm}$ wavelength. The concentration levels of standard solutions were assayed in three intervals. To measure the overall level of flavonoids in the extracts, 0.01-0.02 $\mathrm{g}$ of the extracts was dissolved in methanol $60 \%$, reaching $10 \mathrm{~mL}$. Then, the total level of flavonoids was measured using chloride aluminum colorimetry. However, $1 \mathrm{~mL}$ of the extract was added instead of using the standard solution. The total flavonoid level was calculated in mg per 1 gram extract, equivalent to Rutin (13).

Measurement of the Antioxidant Activity by Beta-carotenelinoleate Method

The beta-carotene-linoleate method was used for measuring antioxidant capacity. In brief, $2 \mathrm{mg}$ of beta-carotene was solved in $0.2 \mathrm{~mL}$ of chloroform and then $20 \mathrm{mg}$ linoleic acid and $200 \mathrm{mg}$ tween 40 were added to the emulsion. In addition, $40 \mathrm{~mL}$ of water saturated with oxygen was added to the above materials. E. helioscopia extract was prepared at a concentration of $0.2 \mathrm{mg}$ per liter in pure ethanol. Next, $4 \mathrm{~mL}$ of the prepared solution was added to $2 \mathrm{~mL}$ of the prepared extract and control (ethanol). Further, the antioxidant activity of the extract was calculated based on the beta-carotene bleaching rate at a wavelength of 470 $\mathrm{nm}$ for 180 minutes (15-minute intervals) by using the following formula and the mean of the obtained values was considered as the percent of the antioxidant activity of the extract.

$A A=100\left[1-\left(A_{0}-A_{t}\right) /\left(A_{00}-A_{0 t}\right)\right]$

$A_{0}$ and $A_{00}$ represent the absorbance of light at time zero. Moreover, $A_{t}$ and $A_{t 0}$ denote the absorbance of light at different times during 180 minutes for the sample and control (12).

\section{Statistical Analysis}

Data were analyzed by one-way ANOVA and Tukey post test using GraphPad Prism software and $P<0.05$ was considered statistically significant.

\section{Results}

Antinociceptive Activity of the Euphorbia helioscopia

The E. helioscopia extract, which was injected in i.p. rout 15 minutes before the injection of formalin, caused pain relief in Balb/C mice. In the first 5 minutes (the first phase, the acute pain step), the difference between control and $8 \mathrm{mg} /$ $\mathrm{kg}$ extract groups was significant $(P=0.031)$. Similarly, the difference between control and 8 or $0.1 \mathrm{mg} / \mathrm{kg}$ groups was significant $(P=0.042)$ in the next 25 minutes (the second phase, the chronic pain step), related data are shown in Figure 2 .

The Effect of Naloxone on the Antinociception Effect of Euphorbia helioscopia Extract

Naloxone alone failed to show an antinociceptive activity compared to the control group. Furthermore, naloxone did not influence the antinociception effect of the dose of 8 $\mathrm{mg} / \mathrm{kg}$ extract (Figure 3).

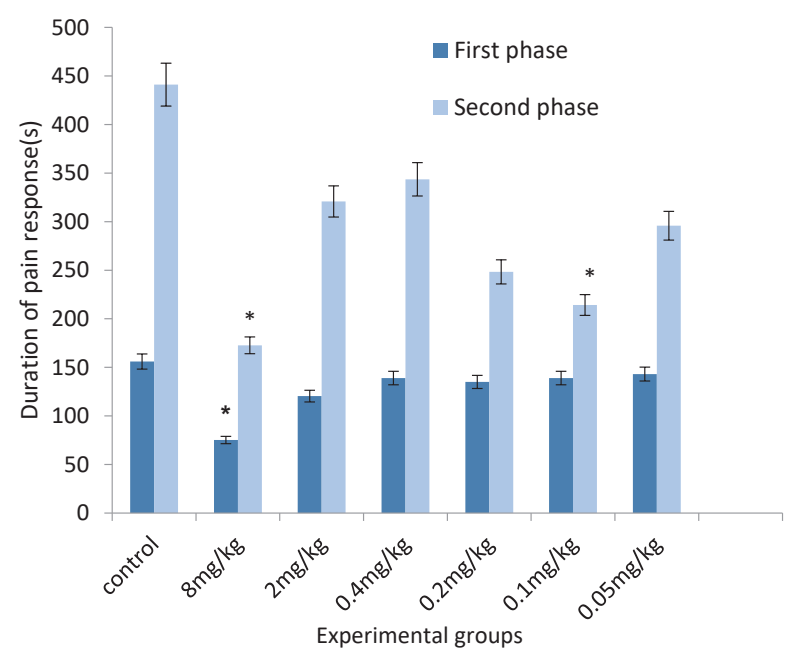

Figure 2. Antinociceptive Activity of Euphorbia helioscopia Evaluated by the Formalin Test.

Note. One-way ANOVA and Tukey tests were applied to identify statistical differences between the means. The bars denoted by the * symbol display a significant difference $(\mathrm{P}<0.05)$ when compared with the control group. The difference between control and $8 \mathrm{mg} /$ $\mathrm{kg}$ extract, as well as control and 8 or $0.1 \mathrm{mg} / \mathrm{kg}$ was significant $(P=0.031$ and $P=0.042$, respectively).

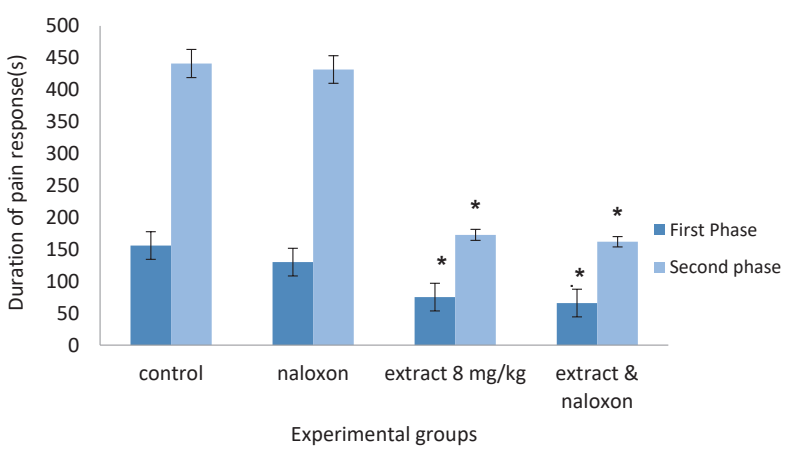

Figure 3. Influence of Naloxone on the Antinociception Effect of Euphorbia helioscopia

Note. One-way ANOVA and Tukey tests were used to identify statistical differences between the means. The bars with the * symbol depict a significant difference $(\mathrm{P}<0.05)$ when compared with the control group. 
The Antioxidant Activity of Euphorbia helioscopia Extract

The antioxidant capacity of the extract was measured in the linoleic acid system. Briefly, $2 \mathrm{~mL}$ of the extract solution with a concentration of $200 \mathrm{mg} / \mathrm{L}$ was added to $1 \mathrm{~mL}$ of $0.1 \mathrm{mM}$ DPPH solution. Six hours after starting the experiment, absorption reached $0.47,0.07,1.205,1.407$, $1.606,1.641$, and $1.57 \%$ in the order of time and it reached its maximum value (1.641) after 60 hours (Figure 4).

Additionally, total phenol and flavonoid were $49.43 \pm 1.8$ $\mathrm{mg}$ GAE$/ \mathrm{g}$ dried extract and $30.19 \pm 1.96 \mathrm{mg}$ rutin $/ \mathrm{g}$ dried extract, respectively.

\section{Discussion}

One of the ways to control pain is using non-steroidal antiinflammatory drugs or narcotic drugs which have relatively high side effects. In addition, opioids in chronic use cause dependence (1). Considering the ease of using medicinal herbs as medication, as well as high complications caused by expensive chemical drugs, herbal medicine has received special attention (4). Opioid analgesia is principally mediated by opioid receptors located in the dorsal root ganglia, spinal cord, and the brain. The receptors expressed on the dorsal horn neurons of the spinal cord are involved in mediating analgesia as opposed to respiratory depression, sedation, nausea, or addiction which involve opioid receptors and mechanisms in other locations (14). In the formalin test, there is a distinctive biphasic nociceptive response that is termed the early and late phase. Drugs that act primarily on the central nervous system inhibit both phases equally while peripherally acting drugs impede the late phase (14). The inhibition of the late phase is due to inflammation with the release of serotonin, histamine, bradykinin, and prostaglandins and, to some degree, the sensitization of central nociceptive neurons (14). The results of the present study demonstrated that the ethanolic extract of E. helioscopia $(8 \mathrm{mg} / \mathrm{kg})$ significantly decreased $(P<0.05)$ in the acute pain response $(0-5$ minutes), and at doses of 0.1 and $8 \mathrm{mg} / \mathrm{kg}$, caused pain relief in the chronic pain response (6-30 minutes) of the formalin test when compared with its control counterpart. Flavonoid compounds are known to possess analgesic and anti-inflammatory properties. It has been suggested that inhibition of arachidonic acid metabolism and antiradical properties are involved in these effects (15). The Euphorbia hirta L. extract exerts central analgesic properties. Such a dose-dependent action was obtained against chemical (the writhing test) and thermic (the hot plate test) stimuli, respectively, from the doses of 20 and $25 \mathrm{mg} / \mathrm{kg}$ and it was inhibited by a naloxone pretreatment, which is a specific morphinic antagonist compound. In addition, an antipyretic activity was obtained at the sedative doses of 100 and $400 \mathrm{mg} / \mathrm{kg}$ on the yeast-induced hyperthermia (15).

The aqueous extract of Euphorbia hirta L was found to have sedative properties since it significantly reduced the

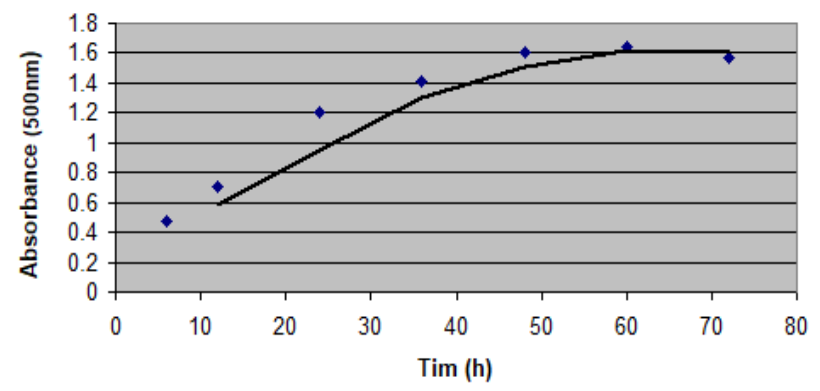

Figure 4. The Antioxidant Activity of Euphorbia helioscopia Extract

general activity of mice in a forcing-test, namely, activitestl, as well as the number of steps climbed and rearings affected by mice confronted to another aversive situation (the staircase test) and the lowest active dose being $100 \mathrm{mg}$ of dried plant $/ \mathrm{kg}$. This sedative activity appears at lower doses (5).

Considering that prostaglandins are important intermediates for producing pain and inflammation, it has been well determined that phenolic compounds, flavonoids, and flavonols inhibit the production of these mediators (16). Given that Euphorbia species are rich in flavonoids and macrocyclic diterpenoids (e.g., cyclooxygenase and lipo-oxygenase inhibitors), at least in part, it is possible that these properties have a role in the painrelieving effect of Euphorbia (7). Studies showed that pain in the acute phase due to the injection of formalin is related to the direct stimulation of pain receptors and the neural activity of type $\mathrm{C}$ fibers. During the chronic pain response, microglia cells activate the release of cathepsin $S$ and cause the release of inflammatory intermediates (17). Further, flavonoids are considered as the inhibitors of nitric oxide synthase and thus prevent the NO-induced production by formalin (18). In the present study, naloxone was unable to reduce the antinociceptive effect of the extract. Therefore, it seems that the opioid system is not involved in the antinociceptive effect of this plant and this plant possibly applied its analgesic effect through prostaglandin reduction or other mechanisms. However, the exact mechanism involved in the antinociceptive activity of this plant needs further evaluation. It seems that flavonoids present in this extract prevent the formation of prostaglandins following the injection of formalin. Thus, more investigations are warranted to clarify the exact underlying mechanisms of the antinociceptive effect of this extract.

\section{Conclusion}

In general, the E. helioscopia extract exhibited an antinociceptive activity. Thus, the present study scientifically validated the traditional use of E. helioscopia in the treatment of pain. Further research work is needed to segregate the active constituents from the extract exhibiting significant analgesic activities. Finally, research regarding 
the mechanism responsible for these activities is also required to guarantee its clinical worth.

Conflict of Interests

The authors declared no conflict of interests.

Acknowledgments

This work was derived from an MSc thesis (Grant No. 714) from the Deputy of Research, Shahrekord University of Medical Sciences.

\section{Ethical considerations}

All the experiments were conducted in accordance with the ethical guidelines on animal experimentation, approved by the Animal Care Ethical Committee of Shahrekord University of Medical Sciences, Shahrekord, Iran (Ethics code: IR.SKUMS.REC 88-7-7).

\section{Authors Contribution}

ZA and ZR conceived and extracted the data, revised the paper, ZL and MR designed the study, $\mathrm{HA}$ analyzed the data and wrote the manuscript. ZA and ZR done all testes.

\section{Funding/Support}

This study was funded by the Research and Technology Deputy of Shahrekord University of Medical Sciences.

\section{References}

1. Woolf CJ. Central sensitization: implications for the diagnosis and treatment of pain. Pain. 2011;152(3 Suppl):S2-15. doi: 10.1016/j.pain.2010.09.030.

2. Croft P, Blyth FM, van der Windt D. Chronic pain epidemiology: from aetiology to public health. Oxford: Oxford University Press; 2010.

3. Law $\mathrm{P}$, Loh $\mathrm{H}$, Wei L-N. Insights into the receptor transcription and signaling: implications in opioid tolerance and dependence. Neuropharmacology. 2004;47:300-11. doi: 10.1016/j.neuropharm.2004.07.013

4. Bahmani M, Shirzad H, Majlesi M, Shahinfard N, RafieianKopaei M. A review study on analgesic applications of Iranian medicinal plants. Asian Pac J Trop Med. 2014;7S1:S43-53. doi: 10.1016/s1995-7645(14)60202-9.

5. Lanhers MC, Fleurentin J, Cabalion P, Rolland A, Dorfman P, Misslin R, et al. Behavioral effects of Euphorbia hirta L.: sedative and anxiolytic properties. J Ethnopharmacol. 1990;29(2):18998. doi: 10.1016/0378-8741(90)90055-x.

6. Uzair M, Loothar BA, Choudhary BA. Biological screening of
Euphorbia helioscopia L. Pak J Pharm Sci. 2009;22(2):184-6.

7. Ramezani M, Behravan J, Arab M, Farzad SA. Antiviral activity of Euphorbia helioscopia extract. J Biol Sci. 2008;8(4):809-13. doi: 10.3923/jbs.2008.809.813.

8. Ahmad VU, Hussain H, Bukhari IA, Hussain J, Jassbi AR, Dar A. Antinociceptive diterpene from Euphorbia decipiens. Fitoterapia. 2005;76(2):230-2. doi: 10.1016/j. fitote.2004.12.014.

9. Barla Demirkoz A, Birman H, Kültür Ş, Öksüz S. Secondary metabolites from Euphorbia helioscopia and their vasodepressor activity. Turk J Chem. 2006;30(3):325-32.

10. Zhang W, Guo YW. Chemical studies on the constituents of the Chinese medicinal herb Euphorbia helioscopia L. Chem Pharm Bull (Tokyo). 2006;54(7):1037-9. doi: 10.1248/cpb.54.1037.

11. Monsef HR, Ghobadi A, Iranshahi M, Abdollahi M Antinociceptive effects of Peganum harmala L. alkaloid extract on mouse formalin test. J Pharm Pharm Sci. 2004;7(1):65-9.

12. Bahmani M, Rafieian-Kopaei M, Parsaei P, Mohsenzadegan A. The anti-leech effect of Peganum harmala L. extract and some anti-parasite drugs on Limnatis nilotica. Afr J Microbiol Res. 2012;6(10):2586-90.

13. Nasri H, Nematbakhsh M, Ghobadi S, Ansari R, Shahinfard N, Rafieian-Kopaei M. Preventive and curative effects of ginger extract against histopathologic changes of gentamicin-induced tubular toxicity in rats. Int J Prev Med. 2013;4(3):316-21.

14. Nestler EJ. Molecular mechanisms of drug addiction. J Neurosci. 1992;12(7):2439-50.

15. Lanhers MC, Fleurentin J, Dorfman P, Mortier F, Pelt JM Analgesic, antipyretic and anti-inflammatory properties of Euphorbia hirta. Planta Med. 1991;57(3):225-31. doi: 10.1055/ s-2006-960079.

16. Hatami K, Yousofvand N, Babaei Garmkhany S. Evaluation of analgesic effects of clove extract on male offspring of surrey female mice during lactation. Armaghane Danesh. 2015;19(10):852-60. [Persian].

17. Hasanvand A, Ahmadizar F, Abbaszadeh A, Amini-Khoei H, Goudarzi M, Abbasnezhad A, et al. The antinociceptive effects of rosuvastatin in chronic constriction injury model of male rats. Basic Clin Neurosci. 2018;9(4):251-60. doi: 10.32598/ bcn.9.4.251.

18. Morshedi A, Dashti-Rahmatabadi MH, Dehghan Harati M, Bagherinasab MA, Salami A. The effect of Artemisia sieberi Besser on inflammatory and neurogenic pain in mice. J Med Plants. 2011;4(40):48-57. [Persian]. 